\title{
GRAMÁTICA NOS LIVROS DIDÁTICOS DE LÍNGUA PORTUGUESA
}

\section{GRAMMAR IN PORTUGUESE LANGUAGE TEACHING BOOKS}

\author{
Emílio de Souza Santos ${ }^{1}$ \\ Leensen Terezinha Pereira Perpetuo ${ }^{2}$ \\ Maria Fernanda Lacerda de Oliveira ${ }^{3}$ \\ Rita Gabriela Vieira ${ }^{4}$ \\ Valéria Daiane Soares Rodrigues ${ }^{5}$
}

\section{RESUMO}

Há uma preocupação cada vez mais latente sobre a forma como a Língua Portuguesa vem sendo abordada nas escolas de educação básica do Brasil, principalmente, em relação ao ensino de conteúdos gramaticais. Nesse contexto, este trabalho tem como objetivo apresentar os resultados de uma pesquisa relacionada à análise de conteúdos gramaticais em livros didáticos de Língua Portuguesa. Para tanto, constituiu-se como corpus da pesquisa os livros Linguagem, Criação e Interação, de Cássia Garcia de Souza e Márcia Paganini Cavéquia, publicado em 2002, e Português Linguagens, de Willian Cereja e Thereza Cochar, publicado em 2015, ambos direcionados ao $6^{\circ}$ ano do Ensino Fundamental. Além do corpus, por tratar-se de uma pesquisa bibliográfica e documental, foram utilizadas contribuições de autores que acenam para a abordagem gramatical no ensino de Língua Portuguesa, especialmente, Barbosa (2009) e Neves (2011). A partir da análise dos livros supramencionados, constatou-se que os materiais didáticos analisados propõem um estudo indutivo dos conteúdos gramaticais, a partir de textos, imagens e propagandas. Vale ressaltar, também, a importância de uma postura crítica do professor em relação à utilização do livro didático como guia de estudo.

\footnotetext{
${ }^{1}$ Licenciado em Letras Espanhol pela Universidade Estadual de Montes Claros e Letras Português pela Universidade Metropolitana de Santos - UNIMES.

E-mail: emiliokenshi@hotmail.com

${ }^{2}$ Graduada em Letras Português pela Universidade Metropolitana de Santos - UNIMES. Professora na Escola Estadual Gilberto Caldeira Brant em Bocaiuva/MG.

E-mail: leentpp@gmail.com

${ }^{3}$ Mestranda em Estudos de Linguagens pelo CEFET - MG. Professora do Departamento de Comunicação e Letras da Universidade Estadual de Montes Claros - UNIMONTES. E-mail: maria.lacerda@unimontes.br

${ }^{4}$ Mestra em Estudos Literários pela Universidade Estadual de Montes Claros UNIMONTES. Professora no Colégio Nossa Senhora do Santíssimo Sacramento em Pirapora/MG. E-mail: ritagabriela74@yahoo.com.br

${ }^{5}$ Mestra em Estudos Literários pela Universidade Estadual de Montes Claros UNIMONTES. Professora do Departamento de Estágios e Práticas Escolares da Universidade Estadual de Montes Claros. E-mail: dai.espanhol@hotmail.com
} 
Palavras-chave: Ensino de gramática. Livro Didático. Língua portuguesa.

\begin{abstract}
There is an increasingly latent concern about the way the Portuguese language has been approached in basic education schools in Brazil, mainly in relation to the teaching of grammatical content. In this context, this work aims to present the results of a research related to the analysis of grammatical content in Portuguese language textbooks. For this purpose, the books Linguagem, Criação e Interação, by Cássia Garcia de Souza and Márcia Paganini Cavéquia, published in 2002, and Português Linguagens, by Willian Cereja and Thereza Cochar, both published in 2015, were constituted as research corpus. 6th year of Elementary School. In addition to the corpus, since it is a bibliographic and documentary research, contributions from authors who used the grammatical approach in the teaching of the Portuguese language were used, especially Barbosa (2009) and Neves (2011). From the analysis of the aforementioned books, it was found that the didactic materials analyzed propose an inductive study of grammatical content, from texts, images and advertisements. It is also worth mentioning the importance of a critical attitude of the teacher in relation to the use of the textbook as a study guide.
\end{abstract}

Key Words: Grammar teaching. Textbook. Portuguese language.

\title{
INTRODUÇÃO
}

Há na contemporaneidade, muitos questionamentos sobre o ensino da gramática na sala de aula. Existe uma maneira certa de ensiná-la? É preciso pensar em como irão reagir os alunos ao modo de ensinar a gramática em sala de aula? Existem diversos estudos sobre este assunto, dada à importância da temática.

O professor depara-se com várias situações, desde alunos que são alfabetizados, que sabem ler e escrever, mas não sabem entender o que estão lendo, e os letrados que compreendem o que lê e o que escrevem e sabem usar a língua no seu meio social. Isso, no ensino da gramática é muito importante, pois o professor de Língua Portuguesa deve preparar o aluno para lidar com o entendimento e compreensão de qualquer texto, tanto oral, quanto escrito. Nesse sentido, a abordagem utilizada para ensinar os conteúdos gramaticais ganha relevância, haja vista que, para alguns alunos, é um tédio estudar gramática; muitos dizem “a gramática da Língua Portuguesa é muito difícil" ou "não consigo aprender", então, algo deve ser mudado, há um problema que deve ser refletido.

Consoante a isso, no presente trabalho, se refletirá sobre esses questionamentos por meio da análise da abordagem da gramática em livros didáticos de Língua Portuguesa para o $6^{\circ}$ ano do Ensino Fundamental. Sendo assim, qual a melhor forma de ensinar a gramática na sala de aula? E como as unidades didáticas abordam o assunto? A partir dessa problematização, então, o estudo objetivou desenvolver análise e reflexão sobre como as unidades didáticas dos livros didáticos utilizados tratam a temática. Para isso, pretendeu-se comparar unidades didáticas de livros de Língua Portuguesa para verificar quais são as possibilidades do estudo gramatical da língua. 
Para se conduzir a pesquisa baseou-se na abordagem qualitativa, de natureza bibliográfica e documental, uma vez que são feitas leituras e revisitações às teorias e pesquisas já concluídas sobre o ensino de gramática e os livros didáticos de língua portuguesa. Além disso, a natureza documental da pesquisa está relacionada ao corpus escolhido para análise. O corpus escolhido foi dois livros didáticos, considerados documentos, pois são registros escritos, fontes de informação, e que permitem uma investigação que abarca leitura, observação, reflexão e crítica sobre o mesmo, de acordo com o que explana Gonçalves (2005) sobre a pesquisa documental. Os livros didáticos escolhidos foram: Português: Linguagens, 6, de William Cereja e Thereza Cochar, publicado em 2015, e Linguagem: criação e interação, $5^{a}$ série, de Cássia Leslie Garcia de Souza e Márcia Paganini Cavéquia, publicado em 2002, ambos da editora Saraiva.

Primeiramente se discorrerá sobre o referencial teórico utilizado para embasar a pesquisa. As análises serão apresentadas, primeiramente, de modo descritivo sobre a unidade didática selecionada em cada um dos livros didáticos, para depois apresentar as comparações feitas sobre trabalho com o estudo da gramática proposto por cada um.

\section{Fundamental Teórica}

A preocupação sobre como ensinar a Língua Portuguesa nas salas de aula das escolas de Educação Básica do Brasil vem motivando importantes discussões e gerando questionamentos e suposições que merecem ser explorados, tendo em vista um processo de ensino aprendizagem mais eficaz.

Segundo Barbosa (2009, p. 31) ensinar a Língua Portuguesa "é compreender o seu funcionamento hoje, e no passado, em um processo dinâmico de capacitação dos alunos para a produção de textos orais e escritos os mais variados". O autor ressalta que aperfeiçoar as habilidades orais e escritas deve ser útil para agir em todos os contextos da atividade social do aluno, como os âmbitos social, profissional e acadêmico.

A partir do texto de Barbosa, percebe-se, também, que atualmente muito se fala de aprimoramento das habilidades no ensino de Língua Portuguesa, ou seja, um aprimoramento necessário que "pouco a pouco, conduz o alunado à formação de seu próprio estilo de escrever cartas, diálogos, páginas eletrônicas” (BARBOSA, 2009, p. 31)”. Isso, levando em conta aspectos ideológicos e reflexões em torno das metodologias no ensino da Língua Portuguesa.

Percebe-se que as aulas de gramática que vem sendo lecionadas nas salas de aula estão se tornando uma transmissão de conteúdos sem bom rendimento, o que deixa o aluno desmotivado a investir em seu estudo. Tal afirmação pode ser comprovada de acordo com Neves (2011), que apresenta em seu livro apresenta o resultado de uma pesquisa feita com 
professores de Língua Portuguesa do Ensino Fundamental e Médio em quatro escolas do estado de São Paulo e refletindo sobre como estes profissionais "usam" a gramática em sala de aula, concluiu que a maioria apenas usa o livro didático sem acrescentar nada ao seu conteúdo.

Ao contrário disso, o ensino da Língua Portuguesa e da gramática deve levar o aluno a refletir, buscar integrá-lo, seja utilizando o seu dia a dia, tentar aproximar o conteúdo do livro com o que o aluno vivencia pode despertar o interesse pela gramática.

Em torno dessa discussão, está agregada a reflexão de aprimoramento deste ensino em sala de aula. Bagno (2000, p. 87) opina que: "A gramática deve conter uma boa quantidade de atividades de pesquisa, que possibilitem ao aluno a produção de seu próprio conhecimento linguístico, como uma arma eficaz contra a reprodução irrefletida e acrítica da doutrina gramatical normativa".

Ainda segundo Bagno,

O ensino de gramática nas escolas acontece de forma extremamente tradicional, devido à aplicação de métodos teóricos, sem significados na vida dos alunos que, por sua vez, não conseguem estabelecer relação entre a teoria gramatical e a prática de texto (BAGNO, 2000, p. 87).

Sendo assim, o ensino da Língua Portuguesa deve se voltar para o uso da língua nas interações cotidianos, bem como deve preocupar-se em capacitar o aluno para a produção de textos orais e escritos fazendo com que seja capaz de desenvolver as atividades estudantis, mas preparando-o, principalmente, para enfrentar as diversas situações comunicacionais de sua vida social, conforme reflexões de Barbosa (2009). Para tanto, o aluno deve ser capaz de reconhecer, ainda que minimamente, os diversos gêneros textuais. Desta forma, acredita-se que é possível que o ensino da gramática da língua se relaciona à aplicabilidade na vida do aluno, principalmente a partir das interações e práticas textuais.

Além disso, este aluno deve conhecer textos de diferentes épocas, que o farão compreender o processo de evolução da língua portuguesa, pois ensinar língua portuguesa sob um viés histórico é importante para que o aluno consiga entender os sentidos relacionados a uma língua transformada, com o tempo, pelos falantes. Assim, conseguirão compreender, por exemplo, o sentido das cantigas medievais. Vale ressaltar, também, que o aluno tem o direito de aprender, na escola, as variedades da língua portuguesa e não apenas uma língua artificial.

Em relação aos erros e acertos no ensino da Língua Portuguesa, Ataliba de Castilho atribui o desempenho dos alunos à atuação do professor e assegura que esse educador passa por três crises que influenciam o seu fazer pedagógico em sala de aula. São elas: a crise social, a científica e a do magistério. 
A crise do magistério diz respeito à desvalorização do professor que trabalha muito, ganha mal e não tem o mesmo status de outras profissões.

No que se refere à crise social, afirma que o êxodo rural fez com que chegasse à escola pessoas que não faziam uso da norma padrão da língua, oportunizando preconceito linguístico para com os falantes populares. Dessa crise social emergem importantes questionamentos: Como valorizar a linguagem popular sem deixar de ensinar a norma culta da língua? O que deve ser ensinado na escola: a língua de prestígio social? Como valorizar a linguagem popular se os materiais de estudo (gramáticas, livros didáticos) faz uso da linguagem culta?

A partir desses questionamentos é importante, com base na contribuição de Barbosa (2009), fazer uma série de críticas em relação aos aspectos relacionados ao ensino da língua portuguesa, tais como: influência do mercado na venda de materiais milagrosos para aprender o português correto, em detrimento de promover uma valorização da diversidade linguística; condenação de usos corriqueiros da língua portuguesa, por profissionais que desconhecem o universo dos cursos de Letras, mas determinam o que é certo ou errado; venda de ensino no Brasil e a definição de usos equivocados da língua ao invés de considerar as variedades relacionadas à multiplicidade de usos.

A fim de dirimir os efeitos negativos desses aspectos, o professor de português deve se atentar para a diferença entre corrigir erros gramaticais quando estiver avaliando uma atividade relacionada ao ensino da norma padrão e o fato de considerar como erro de língua portuguesa os diferentes usos da língua. Além disso, deve ensinar a norma padrão, mas sem desconsiderar outros usos reais da língua.

Quanto à crise do conteúdo, é importante refletir: como fazer com que os futuros professores sejam capazes de adequar os conteúdos teóricos aprendidos na universidade com a realidade da sala de aula? Algumas instituições de ensino superior insistem em ensinar conteúdo gramatical, em detrimento de fazer com que os alunos conheçam as diversas possibilidades comunicacionais da língua.

Neste contexto, é preciso buscar formas mais eficazes de trabalhar a língua portuguesa. Para tanto, é interessante considerar os conhecimentos trazidos pelos professores e pelos alunos, considerando os diversos saberes envolvidos nos tratos da língua a fim de contextualizar, junto aos alunos, exemplos de usos de sentenças gramaticais.

Importante considerar, também, a existência do saber linguístico e saber social. O saber linguístico é compartilhado pela comunidade falante, já o saber social é recebido, inicialmente, no âmbito familiar e depois no âmbito social. Nesse sentido, a linguagem popular deve servir como base para interagir com a tradição escrita da escola. Sobre o saber 
linguístico, é grande a diferença entre a língua usual e o que é prescrito como sendo correto, ocasionando uma distância entre o artificial e o natural, pois:

O conjunto de regras da gramática escolar é uma artificialidade, um conjunto de convenções gráficas, sintáticas, de pronúncia e de variantes morfológicas, conjunto formado por gente de lugares diferentes, de momentos históricos diferentes, de estilos diferentes. (BARBOSA, 2009, p. 39)

Assim, ainda que especialistas renomados sejam incumbidos da tarefa de padronizar a língua a ser ensinada nas escolas e cobrada em vestibulares, por exemplo, é importante que essa língua sirva como ponto de partida para escolhas de outras variantes por parte dos falantes.

O texto "A situação do ensino da gramática nas escolas", constante no livro Gramática na Escola, de Maria Helena de Moura Neves (2011, pp. 9-28), descreve os resultados de uma pesquisa relacionada à escolha do material didático e ao ensino de gramática em escolas de nível Fundamental e Médio do Estado de São Paulo. Alguns aspectos merecem uma reflexão mais aprofundada.

O primeiro aspecto diz respeito ao fato de que não há uma abordagem diferenciada em relação ao trato com a gramática em turmas de nível fundamental e médio. Pode-se considerar esse um fato preocupante se pensarmos que no ensino médio e fundamental o nível dos alunos é distinto. Nesse contexto, o ideal seria uso adequado da metodologia a ser empregada considerando a faixa etária e nível de aprendizagem dos alunos.

Ao propor a pergunta: "Para que se "ensina" a gramática?" os professores responderam que o ensino da gramática está associado a uma "melhor expressão, melhor comunicação, melhor compreensão". Ao analisar os percentuais relacionados a essa primeira pergunta, é interessante refletir sobre o fato de que $30 \%$ dos pesquisados consideram importante à decodificação de regras gramaticais, acenando para a valorização do conhecimento relacionado ao padrão culto, em detrimento de outras finalidades práticas de uso da língua.

Sobre os tipos de exercícios utilizados no exercício da docência, apurou-se que há um predomínio de atividades que acenam para o reconhecimento de classes de palavras e funções sintáticas. A utilização desses exercícios demonstra uma abordagem tradicional de ensino da língua que privilegia um estudo voltado para normatização e que não assegura um ensino contextualizado da gramática.

Em relação aos procedimentos para ensino da gramática, muitos professores apontaram a utilização de textos como ponto de partida. No entanto, os pesquisadores observaram que esses professores utilizavam os textos para retirada de frases as palavras para análise gramatical. Verifica-se, neste contexto, o uso limitado do texto enquanto instrumento 
de ensino aprendizagem. Retirar frases ou palavras para análise não esgota a possibilidade de contextualização da gramática a partir de textos, considerando que estes sinalizam, em grande parte, usos reais da língua. Se bem explorados, os alunos poderiam entender o sentido prático da gramática, internalizando mais facilmente as regras.

\section{Descrição e análise do corpus}

Passaremos a descrever as unidades didáticas escolhidas como corpus para análise e comparação. Foi escolhida a unidade 4 do livro Linguagem: criação e interação e o capítulo 2 da unidade 2 do livro Português: Linguagens. Como critério de escolha observou-se que a unidade e o capítulo escolhidos tinham em comum o estudo da classe gramatical adjetivo, para fins de análise da abordagem de estudo do mesmo. Além dos conteúdos gramaticais das unidades foram analisados a apresentação e o sumário dos dois documentos.

Deste modo, para melhor compreensão e a fim de lograr os objetivos propostas, esta análise foi subdividida em: 1) Organização dos conteúdos e das atividades em cada unidade didática; 2) A apresentação da gramática dentro de cada unidade; e 3) comparação entre a apresentação, o sumário e apresentação da gramática em cada unidade.

\section{1) Organização dos conteúdos e das atividades em cada unidade didática}

No livro Linguagem, Criação e Interação, de Cássia Garcia de Souza e Márcia Paganini Cavéquia, publicado em 2002, destinado à $5^{\mathrm{a}}$ série, atual $6^{\circ}$ ano, observa-se uma apresentação bastante detalhada da estrutura do livro e organização das unidades, com um texto mais formal, e com linguagem que parece estar mais direcionada ao uso pelo professor. As autoras ressaltam a importância do desenvolvimento das destrezas comunicativas: ler, escrever, falar e escutar, do uso da linguagem como forma de comunicação e da diversidade linguística. A partir disso, convida o leitor a explorar o livro didático por meio da seção "conheça seu livro".

$\mathrm{Na}$ continuação, as autoras disponibilizam o sumário que apresenta informações sobre o que será trabalhado em cada unidade. O sumário mostra como o livro didático está dividido: 10 unidades que contém vários tópicos, um Suplemento, um Caderno de análise textual e Bibliografia. Os títulos das unidades são interessantes e sinalizam atividades voltadas para leitura, com assuntos globais ou da própria língua portuguesa: O mundo da leitura; Muitos povos, muitas culturas; A arte de contar histórias; Contos que encantam; Esporte: movimento e diversão; Cidadania e Ação; Uma só humanidade; Fauna: direito a vida; Histórias de arrepiar e Férias à vista. Nos títulos não se observam menções a conteúdos gramaticais. 
Estruturalmente, observam-se os seguintes tópicos: Abertura, Momento do texto (leitura de textos variados), Painel do texto (informações adicionais sobre o texto), Estudo do texto (interpretação do texto), Ampliação do vocabulário (exercitar o uso do vocabulário), Diversidade de expressão (realização de atividades como desenhos, dramatizações, etc.), Questões de linguagem (trabalha a diversidade de uso da linguagem, diferenças entre fala e escrita), Produção de texto (produção de textos), Estudo da língua (estudo de questões gramaticais) e Caderno de análise textual (material complementar para estudo de fábulas, lendas, etc.). Em cada tópico há uma explicação detalhada do que o aluno encontrará nas unidades do livro, contendo, inclusive, exemplos para facilitar a compreensão.

Em "Momento do texto" é apresentado apenas um texto, por exemplo, na unidade 4, o texto "Hoz malepon viuh echer ou o caçador" do autor Flávio de Souza.

No "Painel do texto" há uma apresentação sobre o autor e suas principais obras, acrescido de mais dois pequenos textos informativos irão auxiliar na compreensão do texto.

Barbosa (2009) afirma que o professor de língua portuguesa é responsável por ensinar os seus alunos a entender o sentido dos textos, compreendendo toda uma história por trás da escrita; que é o autor, quando foi escrito, por que foi escrito, entre outras informações. Ao explorar nos subtítulos "Momento do texto" e "Painel do texto", os autores Souza e Cavéquia (2002), mesmo que o livro tenha sido publicado antes, aproximaram do pensamento de Barbosa.

No "Estudo de Texto", tem-se a interpretação do texto. Algumas perguntas são formadas com definições que podem auxiliar na resolução da questão, como a explicação do que é paródia, personagens e narrador, por exemplo. Existem subdivisões nessa parte, como "Do autor ao leitor" que apresenta algumas características do autor; na subdivisão "O diálogo entre os textos" encontramos outro tipo de texto, por exemplo na unidade quatro, um cartum, que é comparado com o texto principal. Em "Indo além" tem-se outro texto que explorou sobre as profissões retomando assim o texto principal em que o caçador segue a profissão do pai, do avô etc.

$\mathrm{Na}$ "Ampliação do Vocabulário", da unidade 4, temos o uso do dicionário e explicação de como usá-lo.

Em “Questões de Linguagem” apresentamos algumas situações da língua que compara e trabalha com significados, no qual é retirado uma passagem do texto e compara com outros textos.

Na seção "Produção de texto", a redação pedida é de acordo com o tipo de texto que está sendo trabalhado, apresentam outro texto do mesmo gênero textual. Nela, há um subitem que é "Leitura", na qual um livro é citado como sugestão de leitura. 
No item "Estudo da Língua", tem-se a gramática e a ortografia. Na gramática, conforme a unidade 4, há pequenas orações em um contexto, não faz menção ao texto principal da unidade, há algumas perguntas que tenta levar o aluno a entender o conteúdo gramatical que está sendo trabalhado, depois é apresentada uma definição. Em “Ortografia”, é retirado do texto principal os itens trabalhados na ortografia. Há um subitem chamado "Desafio" que trabalha a gramática estudada na unidade.

Todos os itens na unidade procuraram trabalhar não somente com o texto principal, mas como o gênero textual que foi apresentado, trabalhando, assim, diversos textos de mesmo gênero em uma unidade.

O livro Português Linguagens, de Willian Cereja e Thereza Cochar, publicado em 2015, destinado a alunos do $6^{\circ}$ ano, traz na apresentação um chamado a todos os tipos de leitores. A frase inicial "Este livro foi escrito para você" é seguida pela especificação de leitores de todos os tipos: curiosos, para quem gosta de trabalhar individualmente ou em grupos, para quem é plugado no mundo, para quem é dinâmico e criativo, entre outros atributos, sinalizando uma diversidade de aspectos pensados na tentativa de atender a todos. Desta forma, utiliza uma apresentação mais próxima ao aluno.

Na sequência, os autores apresentam o sumário, organizados por unidades, subdividas em capítulos. O livro está organizado em quatro unidades: "No mundo da Fantasia” (capítulos I, II e III, respectivamente: Era uma vez, Pato aqui, pato acolá e ò princesa, jogue-me suas...); Crianças (capítulo I, II e III, respectivamente: O fazendeiro da cidade, Entre Irmãos e Ensaios da Vida) Descobrindo quem sou eu (capítulo I, II e III, respectivamente: No frescor da Inocência, $\mathrm{O}$ preço de pensar diferente e $\mathrm{O}$ eu que existe em mim) Verde, adoro ver-te (capítulo I, II e III, respectivamente: Asas da liberdade, A natureza pede socorro e Natureza no museu). Cada unidade tem um tema que será retomado nos textos dos capítulos.

As unidades, de forma geral, apresentam os seguintes tópicos: Estudo do texto (trabalha interpretação, os tipos de linguagens, etc.), Produção de texto, A língua em foco, De olho na escrita, Divirta-se, Para escrever com expressividade, Para escrever com adequação, De olho na escrita e Para escrever com coerência e coesão. Esses tópicos variam conforme os capítulos. Importante mencionar ainda um tópico intitulado "Passando a limpo", que traz alguns projetos: Projeto: histórias de hoje e sempre; Projeto: Quadrinhos: eu também faço; Projeto: eu também faço história etc. Os títulos das unidades são interessantes e adequados para o público alvo: No mundo da fantasia; Crianças; Descobrindo quem sou eu; Verde, adoro ver-te. 
Com base na unidade 2, o capítulo 2 começa com uma informação que será tratada no texto logo a seguir. Depois, uma explicação de onde o texto foi retirado. No capítulo em questão foi um trecho do livro "A mala de Hana".

Logo após o texto, encontra-se o "Estudo Dirigido" que está dividido em três subtítulos: "Compreensão e Interpretação", "A linguagem do texto" e "Leitura expressiva do texto". Em "Compreensão e Interpretação" é feito o estudo do texto e comparações do texto com o contexto histórico em que vivem os personagens. Em "Linguagem do texto", encontramos exercícios que trabalham o sentido das palavras, das frases. Já em "Leitura expressiva do texto" pede-se para que o aluno leia os dois últimos parágrafos prestando atenção na pontuação. Este subtítulo tem outro item chamado "Trocando ideias". São perguntas que são feitas ao leitor, dessa forma faz com que o leitor se ponha no lugar do personagem, com perguntas de como eles reagiriam naquela situação.

Em "Produção de Texto", são trabalhos diversos tipos de gêneros de textos, como relatos, diário, quadrinhos, artigo de opinião, conto etc. No capítulo 2 , a produção de texto é sobre Quadrinhos, e nele há várias explicações do que encontramos nos quadrinhos, como balões, legendas, interjeições e onomatopeias. Há alguns exercícios e ao final pede-se para que os alunos criem um quadrinho no item "Agora é a sua vez".

No capítulo 2, da unidade 2 temos ainda o item "Para escrever com adequação". Nele há dois textos, um diálogo e uma história em quadrinhos, com exercícios de interpretação de textos e algumas informações de como usar o travessão e alguns verbos, neste item eles tratam qual a forma mais adequada para se escrever determinada oração.

A seção "A língua em foco" aborda o estudo a gramática. Eles dividem este subitem em "Construindo o conceito", "Conceituando", "Exercícios", "Semântica e Discurso" e "De olho na escrita". Em "Construindo o conceito", os autores tentam por meio de uma imagem, e perguntas, chegar a um conceito do item gramatical que será estudado - no caso do exemplo, o Adjetivo. Em "Conceituando", por meio da imagem e das perguntas anteriores, os autores constroem uma definição. Logo após, apresenta alguns exercícios, depois mais definições e classificação e por fim mais exercícios. Em "Semântica e Discurso" encontramos exercícios sobre os significados das palavras e seu uso. Já em "De olho na escrita" há o estudo da ortografia ou da fonética, por meio de texto e exercícios.

Em "Divirta-se" são trabalhadas informações que levarão o aluno a se divertir, como exemplo, no capítulo mencionado o título da atividade dessa seção é “Olho Mágico”.

No item "Intervalo", segundo o sumário é trabalho um projeto diferente em cada unidade. 


\section{2) A apresentação da gramática dentro de cada unidade}

No livro Linguagem, Criação e Interação, de Cássia Garcia de Souza e Márcia Paganini Cavéquia, a gramática começa a ser trabalhada no estudo do texto, no qual os alunos passam a observar categorias gramaticais a partir da interpretação do texto lido, como podemos observar no estudo do texto do capítulo 4 - Hoz Malepon Viuh Echer ou o caçador. $\mathrm{Na}$ questão 8 da atividade, as autoras pedem que os alunos identifiquem os diminutivos e expliquem o motivo de uso dos termos. Na questão 9, é pedido aos alunos que identifiquem uma palavra que substitua o substantivo caçador. Essas duas atividades abordam o conteúdo gramatical de maneira indutiva, abrangendo também conhecimentos de semântica e classes gramaticais.

O livro Linguagem, Criação e Interação, de Cássia Garcia de Souza e Márcia Paganini Cavéquia, trabalha explicitamente as questões gramaticais no tópico "Estudo da Língua". No capítulo disponibilizado para análise, o autor propõe estudo dos adjetivos. É interessante mencionar que o autor parte de textos para explicar o que são substantivos, para, na sequência, explicar que o adjetivo serve para qualificar esse substantivo. Além disso, aborda outros assuntos gramaticais como os encontros consonantais e vocálicos, além de questões sobre as dificuldades ortográficas. Os assuntos gramaticais são trabalhados após a seção de produção de texto com a finalidade de tirar as dúvidas dos alunos. Importante considerar, também a diversidade na utilização de gêneros textuais: anúncio, charge, imagem, entre outros.

No livro Português Linguagens, de Willian Cereja e Thereza Cochar, observa-se que a abordagem gramatical é feita a partir do estudo do texto na seção "A linguagem do texto" trabalhando as questões textuais com a utilização de palavras e seus significados a partir de enunciados retirados do texto. A gramática é abordada no tópico "A língua em foco" por meio de atividades indutivas. No capítulo analisado, observa-se, também, a proposição de estudar o conteúdo “adjetivo". Para tanto, os autores disponibilizam, inicialmente, uma imagem para construção do conceito. É perceptível um diálogo entre a imagem e o estudo da classe gramatical "adjetivo". Além da classe gramatical, os autores propõem atividades visando compreender a utilização do adjetivo na construção textual e o seu estudo na semântica e no discurso. Os autores abordam também sobre os encontros consonantais. Percebe-se, também, uma diversidade de gêneros textuais: história em quadrinhos, cartaz, charge etc.

\section{3) Comparação entre a apresentação, o sumário e apresentação da gramática em cada unidade}


O livro Linguagem, Criação e Interação, de Cássia Garcia de Souza e Márcia Paganini Cavéquia e o livro Português Linguagens, de Willian Cereja e Thereza Cochar apresentam algumas distinções em relação à apresentação, ao sumário e a forma como a gramática é apresentada.

No que se refere à apresentação, o primeiro salienta o convite para que o aluno adentre no universo da leitura, de forma reflexiva e crítica. Após essa curta apresentação, disponibiliza de forma bastante detalhada a sequência de abordagem das questões propostas. Já o segundo, traz uma apresentação mais longa e bastante direcionada aos alunos, mas não apresenta informações adicionais sobre a organização das unidades do livro.

Sobre o sumário, no primeiro livro observa-se a existência de tópicos fixos em todas as unidades, nos quais se demonstra o passo a passo das atividades propostas. Ao todo são 8 tópicos (momento do texto, painel do texto, estudo do texto etc.). No segundo livro, os tópicos variam conforme os objetivos e tipos de texto dos capítulos (estudo do texto, produção de texto etc.). Apresenta uma quantidade menor de tópico e, consequentemente, um menor detalhamento das ações propostas.

Em relação à forma como a gramática é apresentada, no primeiro livro, o trabalho com gramática fica disponibilizada no tópico "estudo da língua”, sempre no final de cada unidade. Não se observou nos outros tópicos de cada unidade uma abordagem gramatical mais direta. Quanto ao segundo livro, é disponibilizado um tópico para estudo da gramática “A língua em foco". No entanto, ao longo de todo o capítulo está perceptível o trabalho com estudo da gramática de forma contextualizada, como por exemplo, no tópico "Para escrever com adequação":

3. Observe na fábula o diálogo entre os animais.

A) Que sinal de pontuação indica o início da fala de cada personagem?

B) Para indicar quem está falando, o narrador emprega certos verbos, como dizer, presente neste trecho "A raposa adiantou-se e disse". Identifique no texto outros verbos que marcam a fala dos personagens" (CEREJA; COCHAR, 2015, p. 109).

Assim como o trecho disposto acima, há outros que abordam o uso da gramática, de forma contextualizada, a partir dos textos.

De forma geral, a gramática nos capítulos estudados nos dois livros, apresentam imagens, propagandas ou pequenos textos seguidos por perguntas que tentam fazer com que o aluno deduza e compreendam o conteúdo gramatical que será trabalhado. Logo após, apresentam uma definição e alguns exercícios.

\section{Considerações finais}


O desenvolvimento do presente estudo possibilitou analisar duas unidades didáticas Linguagem, Criação e Interação, de Cássia Garcia de Souza e Márcia Paganini Cavéquia, publicado em 2002, e Português Linguagens, de Willian Cereja e Thereza Cochar, publicado em 2015, ambos direcionados ao $6^{\circ}$ ano do Ensino Fundamental. Além disso, também permitiu analisar textos de Barbosa (2009), Bagno (2000) e Souza (2002) referentes ao estudo da gramática na sala de aula.

As duas unidades didáticas apresentaram algumas distinções tanto em relação à apresentação, como no sumário e a forma como a gramática é disponibilizada no livro.

De modo geral, a gramática apresentada no primeiro livro, tem um tópico "estudo da língua", sempre no final de cada unidade, e não apresentou em outros tópicos uma abordagem gramatical mais direta. Quanto ao segundo livro, é disponibilizado um tópico para estudo da gramática "A língua em foco". No entanto, ao longo de todo o capítulo é perceptível o trabalho com estudo da gramática de forma contextualizada, como por exemplo, no tópico "Para escrever com adequação".

Sendo assim, pode-se inferir, pelas análises descritas que o professor tem o papel de tentar adequar o conteúdo que está lhe sendo apresentado na unidade didática ao tipo de alunado que se tem em sala de aula, pois vários aspectos devem ser analisados inclusive o meio social em que vive o aluno. Assim, a metodologia do professor ao ensinar gramática, junto ao trabalho proposto pelos livros didáticos, passa a fazer diferença na aprendizagem e a contribuir na transformação de um aluno alfabetizado para letrado, colaborando para que saiba lidar com qualquer situação de leitura e escrita, sobretudo ao entendimento do que ler A unidade didática poderá trazer uma menção a esse meio, mas irá abranger de forma geral, enquanto o professor poderá adequá-la a situação que lhe é apresentado.

Depreende-se, ainda, que os livros didáticos trazem uma abordagem indutiva, na qual o aluno deve, a partir de exemplos e contextos, chegar a uma conceituação e entendimento sobre o conteúdo gramatical que está sendo estudado. Desta forma, o aluno consegue perceber a aplicabilidade de determinado conteúdo na prática e em diversos contextos de usos sociais em que se insere. Ao perceber a usabilidade do que se ensina a escola, o aluno se torna mais interessado pelo estudo da língua, pois será mais atrativa, uma vez que sabe que contribuirá significativamente para a sua aprendizagem, transformando-se em um estudante letrado além de alfabetizado, podendo atuar e colaborar nas diversas situações de uso da língua do seu dia a dia. 


\section{Referências}

BAGNO, Marcos. Dramática da Língua Portuguesa. São Paulo: Ed. Loyola, 2000.

BARBOSA, Afrânio Gonçalves. Saberes gramaticais na escola. In: VIEIRA, Silvia Rodrigues; BRANDÃO, Silvia Figueiredo (Orgs.). Ensino de gramática: descrição e uso. 2. ed. São Paulo: Contexto, 2009. pp. 30-42

CEREJA, Willian Roberto; COCHAR, Thereza Magalhães. Português: linguagens, 6. 9. ed. reform. São Paulo: Saraiva, 2015.

GONÇALVES, Hortência de Abreu. Manual de metodologia da pesquisa científica. São Paulo: Avercamp, 2005.

NEVES, Maria Helena de Moura. Gramática na escola. 9. ed. São Paulo: Contexto, 2011. p.9-28

SOUZA, Cássia Leslie Garcia de; CAVÉQUIA, Márcia Paganini. Linguagem: criação e interação $-5^{\text {a }}$ série. 3. ed. São Paulo: Saraiva, 2002.

Artigo recebido em: 25/01/2020.

Artigo aceito em: 02/03/2020. 